\title{
Analisis Makna Dan Fungsi Mantra Pengobatan Di Desa Kaleo Kecamatan Lambu
}

\author{
Arwan $^{1}$, Nurul Istiqomah ${ }^{2}$ \\ ${ }^{12}$ STKIP Harapan Bima, Bima, Indonesia \\ Email: daewan186@gmail.com ${ }^{1}$, istiqomah.nurul29@gmail.com²
}

\begin{abstract}
This study aims to describe the structure of the meaning and function of treatment spells in Kaleo Village, Lambu District, Bima Regency. The treatment spells in Kaleo village have special characteristics and forms that are different from other areas of Bima. The healing spells in Kaleo village have various variations according to the illness, such as stomachache spells, smallpox spells, fever spells, fracture treatment spells, wound healing spells, and others. These spells cannot be recited by just anyone and are passed down from generation to generation by the sando family. Before chanting the spells, the patient must notify the handler/sando or shaman of the illness so that the sando can recite the appropriate spell. The method used in this research is descriptive method. This method aims to collect, clarify, and analyze data in order to obtain an overview of the types, meanings, and functions of healing spells in the village of Kaleo, Lambu, Bima. This research uses a holistic folklore approach. This approach pays attention to two aspects, namely folk and lore. Based on the data collection process, the results obtained that the treatment spells in Kaleo village were not only transmitted orally but also through writing. However, even though the writing can be read by people, the spell writing will not bring any benefits other than being read by the handler/sando. These spells function for the treatment of stomach pain, smallpox treatment spells, fracture treatment spells, wound healing spells, ncara oi (fever) treatment spells, and treatment spells for jinn and demon disorders. These spells are very effective when recited by the handler or sando and are believed to have efficacy to treat the types of ailments mentioned above experienced by the local village community.
\end{abstract}

Keywords: treatment spells, meanings, function, Kaleo.

\begin{abstract}
Abstrak
Penelitian ini mengkaji tentang struktur makna dan fungsi mantra di Desa Kaleo Kecamatan Lambu Kabupaten Bima. Mantra pengobatan di desa Kaleo memiliki ciri dan bentuk khusus yang berbeda dengan wilayah Bima lainnya. Mantra pengobatan di desa Kaleo, memiliki variasi yang beragam sesuai dengan sakit yang diderita, seperti mantra sakit perut, mantra cacar, mantra demam, mantra patah tulang, mantra luka-luka, dan lain-lain. Mantra-mantra ini tidak dapat dibacakan oleh sembarang orang dan diturunkan turun temurun oleh keluarga pawang/sando. Sebelum dibacakan mantra, pasien harus memberitahu pawang/sando atau dukun penyakit yang diderita sehingga pawang/sando dapat membacakan mantra yang sesuai. Metode yang digunakan dalam penelitian ini adalah metode deskriptif. Metode ini bertujuan untuk mengumpulkan, mengklarifikasi, dan menganalisis data sehingga diperoleh gambaran mengenai jenis, makna, dan fungsi mantra pengobatan di desa Kaleo, Lambu, Bima. Penelian ini menggunakan pendekatan folklor yang bersifat holistik. Pendekatan ini memperhatikan dua aspek, yaitu folk dan lore. Berdasarkan proses pengumpulan data hasil yang di dapatkan bahwa mantra-mantra pengobatan di desa Kaleo tidak hanya disebarkan melalui lisan tetapi juga melalui tulisan. Akan tetapi, meskipun tulisan tersebut dapat dibaca oleh orang, tulisan mantra tersebut tidak akan membawa khasiat selain dibacakan oleh pawang/sando. Mantra-mantra tersebut berfungsi untuk pengobatan sakit perut, mantra pengobatan sakit cacar, mantra pengobatan patah tulang, mantra pengobatan luka-luka, mantra pengobatan ncara oi (demam), dan mantra pengobatan gangguan jin dan setan. Mantra-mantra tersebut sangat ampuh apabila dibacakan oleh pawang atau sando dan dipercaya memiliki kasiat untuk mengobati jenis-jenis sakit disebutkan di atas yang dialami oleh masyarakat Desa setempat.
\end{abstract}

Kata Kunci: Mantra Pengobatan; Makna; Fungsi; Kaleo.

\section{PENDAHULUAN}

Setiap daerah di Indonesia memiliki kekayaan budaya. Menurut Koentjaraningrat (dalam Asmarini, 1998: 1), kebudayaan paling sedikit memiliki tiga wujud, yaitu (1) wujud kebudayaan sebagai kompleks ide, gagasan, nilai, norma, peraturan dan sebagainya, (2) wujud kebudayaan sebagai suatu kompleks aktivitas kelakuan berpola dari manusia dalam masyarakat, (3) wujud kebudayaan sebagai benda-benda hasil karya manusia. Wujud kebudayaan pertama disebut wujud ide, yang kedua disebut sistem sosial, dan wujud kebudayaan ketiga disebut kebudayaan fisik. Sebelum Indonesia mengenal budaya baca-tulis, budaya lisan berkembang pesat dan diwariskan 
secara turun temurun oleh nenek moyang. Tradisi lisan adalah segala wacana yang disampaikan secara lisan, mengikuti cara atau adat istiadat yang memola dalam suatu masyarakat (Duija, 2005: 113). Menurut Pudentia (dalam Duija, 2005: 114), tradisi lisan mencakup segala hal yang berhubungan dengan sastra, bahasa, sejarah, biografi, dan berbagai hal yang disampaikan dari mulut ke mulut. Oleh karena itu, dapat dipahami bahwa sastra lisan, merupakan bagian dari suatu kebudayaan yang hidup dan berkembang di tengah-tengah masyarakat serta diwariskan dan disebarkan secara turun-temurun dari generasi ke generasi berikutnya secara lisan. Sastra lisan mengandung nilai yang berharga bagi kehidupan masyarakat.

Bima merupakan salah satu daerah di wilayah Nusa Tenggara Barat yang juga kaya akan tradisi dan budaya, termasuk sastra lisan. Sastra lisan yang berkembang di Bima adalah mpama kade'e (dongeng), mpama pehe (tekateki), kapatu (pantun), rawa (nyanyian rakyat), dan mantra. Mantra adalah sastra lisan yang berbentuk puisi dan termasuk dalam jenis folklor.

Folklor berasal dari dua kata, yaitu folk yang berarti collectivity (kolektif) dan lore yang menurut Dundes (dalam Danandjaja: 2002: 1) adalah sekelompok orang yang memiliki ciriciri pengenal fisik, sosial, dan kebudayaan sehingga dapat dibedakan dari kelompok lainnya. Ciri-ciri folklor menurut Bruvand (dalam Endraswara, 2009: 20) adalah bersifat oral (lisan), bersifat tradisional, keberadaannya sering memiliki varian atau versi, selalu anonim, dan cenderung memiliki formula atau rumus yang jelas. Selain itu, menurut Bascom (1965: 279-298), folklor memiliki beberapa fungsi, yaitu sebagai cermin atau proyeksi angan-angan pemiliknya, sebagai alat pengesah pranata dan lembaga kebudayaan, sebagai alat pendidikan, dan sebagai alat penekan berlakunya tata nilai masyarakat dan pengendalian perilaku masyarakat. Fungsi terpenting folklor adalah sebagai tata kelakuan kolektif.

Adapun mantra menurut Sorayah (2014: 3), secara harfiah, mantra berarti kegiatan membebaskan pikiran. Dari sisi istilah, mantra berarti bunyi, kata, frasa,atau kalimat yang digumamkan, dibisikkan, diucapkan, dinyanyikan dengan cara berulang-ulang, diyakini mempunyai kekuatan sebagai sarana untuk berkomunikasi dengan Tuhan dan bermanfaat untuk tujuan perapalnya (pengucapaan atau pembacaannya). Mantra dipercaya mengandung kekuatan gaib dan penuh dengan misteri. Mantra tidak dapat diucapkan oleh sembarang orang, melainkan hanya diucapkan oleh dukun dan pawang. Dengan demikian, dapat dipahami bahwa mantra memiliki manfaat sesuai dengan tujuan dukun atau pawang yang merapalkannya.

Mantra-mantra Bima dipengaruhi oleh agama Hindu, agama Islam, dan kepercayaan nenek moyang Bima. Karena itu, mantra Bima mengandung diksi bahasa Bima dan bahasa Arab. Berdasarkan manfaat dan fungsinya, jenis-jenis mantra yang terdapat di Bima adalah mantra pengasihan, mantra perlindungan diri, mantra ketidakberdayaan atau kesakitan, mantra kekebalan tubuh, mantra jodoh, mantra balas jodoh, dan mantra pengobatan (Sirat, 2015: 4). Mantra pengasih digunakan untuk memohon pertolongan dan kasih dari Tuhan. Mantra perlindungan diri dibacakan untuk kesaktian batin seseorang. Mantra ketidakberdayaan atau kesakitan dibacakan ketika berada di pengadilan atau sebelum memulai perkelahian. Mantra jodoh diyakini dapat mendatangkan jodoh. Sedangkan mantra balas jodoh adalah mantra yang dibacakan untuk membalas jodoh dan mengharap kehidupan yang baik setelah pernikahan. Adapun mantra pengobatan dibacakan untuk menghilangkan rasa sakit dan mendapatkan kesembuhan.

Desa Kaleo merupakan salah satu desa yang berada di wilayah kecamatan Lambu, Kabupaten Bima. Seperti halnya wilayah Bima lainnya, desa Kaleo juga memiliki mantramantra lama, salah satunya mantra pengobatan. Mantra pengobatan di desa Kaleo memiliki ciri dan bentuk khusus yang berbeda dengan wilayah Bima lainnya. Mantra-mantra pengobatan di desa Kaleo, Kecamatan Lambu, Kabupaten Bima, memiliki variasi yang beragam sesuai dengan sakit yang diderita oleh pasien, seperti mantra sakit perut, mantra cacar, mantra demam (ncara oi), mantra patah tulang, 
mantra luka-luka, dan mantra pengobatan gangguan jin dan setan. Mantra-mantra ini tidak dapat dibacakan oleh sembarang orang melainkan diturunkan secara turun temurun oleh keluarga pawang mantra. Sebelum dibacakan mantra, pasien harus menyampaikan kepada pawang/sando penyakit yang diderita agar pawang/sando dapat membacakan mantra yang sesuai.

Penelitian mengenai mantra di Bima telah dilakukan oleh beberapa peneliti, tetapi penelitian mengenai mantra pengobatan di desa Kaleo kecamatan Lambu belum dilakukan sebelumnya. Akan tetapi, meski berbeda fokus dan tujuan, penelitian-penelitian mengenai mantra di Bima dapat menjadi referensi yang bermanfaat bagi penelitian ini.

\section{METODE}

Metode yang digunakan dalam penelitian ini adalah metode deskriptif. Metode ini bertujuan untuk mengumpulkan, mengklarifikasi, dan menganalisis data sehingga diperoleh gambaran mengenai jenis, makna, dan fungsi mantra pengobatan di desa Kaleo, Lambu, Bima. Penelian ini menggunakan pendekatan folklor yang bersifat holistik. Pendekatan ini memperhatikan dua aspek, yaitu folk dan lore. Ada tiga tahapan yang dilakukan dalam pendekatan folklor, yaitu pertama tahap persiapan atau penelitian di tempat, yaitu melakukan penelitian kepustakaan, mengumpulkan informasi mengenai Mantra Pengobatan, dan mempersiapkan penelitian di lapangan. Tahap kedua adalah penelitian di lapangan, yaitu mengumpulkan data dengan merekam penuturan mantra pengobatan, wawancara, dan melakukan pengamatan. Tahap ketiga adalah tahap pengarsipan dan penyusunan kajian (Amir, 2013: 149-153).

Populasi dalam penelitian ini adalah keseluruhan mantra pengobatan yang terdapat di desa Kaleo kecamatan Lambu. Sampel penelitian ini adalah mantra pengobatan sakit perut, mantra pengobatan cacar air, mantra pengobatan sakit mata, mantra sakit gigi, mantra memudahkan bersalin. Sumber data didapatkan dari pawang/sando yang terdapat di desa Kaleo yang mengetahui tentang mantra-mantra pengobatan.
Teknik yang dilakukan dalam pengumpulan data adalah pengamatan dan pencatatan. Pengamatan saja tidak cukup karena indera manusia terbatas, karena itu dibantu oleh pencatatan. Selain itu, teknik rekam dilakukan dengan mewawancara informan dan merekamnya dengan menggunakan recorder yang terdapat di handphone (HP). Teknik wawancara digunakan peneliti sastra lisan untuk menggali data dan informasi tentang pengalaman hidup individu, pemerolehan mantra yang dibaca, dan unsur-unsur kebudayaan masyarakat setempat (Sudikan, 2001: 176). Proses pengumpulan data dilakukan dengan mendatangi lokasi penelitian, desa Kaleo, dan mewawancarai pihak-pihak yang dijadikan sumber data.

Informan dalam penelitian sastra lisan terdiri dari dua, yaitu informan kunci yang merupakan figure yang memegang peran penting dalam sastra lisan, misalnya dalang, pemuka masyarakat, sesepuh, dan pelaku lain. Tokoh-tokoh ini biasanya memegang peranan sebagai informan kunci. Sedangkan informan biasa merupakan orang biasa yang menjadi pendukung sastra lisan. Orang-orang ini mungkin menjadi penikmat sastra lisan (Endraswara, 2009: 220).

Setelah data-data dikumpulkan, datadata tersebut diolah berdasarkan langkahlangkah berikut.

1. Data-data yang diperoleh dari studi pustaka diinventarisasi.

2. Data rekaman dipindah dari bentuk lisan ke bentuk tulisan.

3. Transkripsi karya sastra dipisahkan dari transkripsi wawancara dengan informan.

4. Data karya sastra kemudian diterjemahkan untuk memudahkan pemahaman pembaca.

5. Data-data yang telah diolah kemudian analisis agar dapat dipahami makna dan fungsinya.

\section{HASIL DAN PEMBAHASAN}

Berdasarkan proses pengumpulan data yang dilakukan, didapatkan bahwa mantramantra pengobatan di desa Kaleo tidak hanya disebarkan melalui lisan tetapi juga melalui tulisan. Akan tetapi, meskipun tulisan tersebut dapat dibaca oleh orang, tulisan mantra tersebut 
tidak akan membawa khasiat selain dibacakan oleh pawang/sando.

Adapun mantra-mantra pengobatan yang ditemukan di desa Kaleo kecamatan Lambu adalah mantra pengobatan sakit perut, mantra pengobatan sakit cacar, mantra pengobatan patah tulang, mantra pengobatan luka-luka, mantra pengobatan ncara oi (demam), dan mantra pengobatan gangguan jin dan setan.

\section{Analisis Makna dan Fungsi Mantra Pengobatan}

1. Mantra Pengobatan Sakit Perut

Bismillahirrahmanirrahi

Tapu na woke

Uma na mila

Rade na kalubu

Bareka laa ilaaha illalla bareka muhammada rasululla

Artinya:

Dengan menyebut nama Allah yang Maha Pengasih lagi Maha Penyayang

Talinya pusar

Rumahnya buluh

Kuburannya kelabu

Berkah dari Allah Tiada Ilah Selain Allah dan berkah Muhammad Rasulullah

Mantra pengobatan sakit perut ini dipengaruhi oleh agama Islam. Hal tersebut terlihat dari larik pembuka dan penutup yang menggunakan bahasa Arab dan menyebut nama Allah SWT dan Nabi Muhammad SAW. Bacaan basmalah digunakan untuk memulai bacaan mantra yang menandakan pawang/sando mengharapkan bantuan dari Allah SWT untuk memberikan kesembuhan dari penyakit. Larik kedua, tapu na woke (talinya pusar) bermakna mencari atau memeriksa penyakit yang terdapat di dalam perut pasien yang dimulai dari pusar. Sebelum pemeriksaan dimulai, pasien harus menyampaikan kepada pawang/sando mengenai penyakit yang diderita. Adapun di larik ketiga, uma na mila (rumahnya buluh) bermakna bahwa semua penyakit yang terdapat di dalam perut (rumah buluh) akan ditarik keluar secara perlahan-lahan. Larik keempat, rade na kalubu (kuburannya kelabu) bermakna bahwa semua penyakit yang terdapat di perut pasien musnah dan dibuang ke kuburan. Mantra ini kemudian ditutup oleh larik yang bermakna mengharap berkah dari Allah SWT dan Nabi Muhammad SAW.

Adapun fungsi dari mantra ini tergantung pada tujuan dibacakannya mantra, yaitu untuk mengobati penyakit perut yang diderita oleh pasien. Ketika mantra dibacakan, pawang/sando terlebih dahulu menyebut nama Allah yang menandakan bahwa sando mengharapkan bantuan dari Allah SWT untuk menyembuhkan penyakit pasien. Larik kedua, ketiga, dan keempat menunjukkan hubungan antara manusia dan alam, sedangkan larik terakhir menunjukkan hubungan antara manusia dan Allah SWT. Mantra pengobatan sakit perut ini umumnya diturunkan turun temurun oleh keluarga pawang/sando.

2. Mantra Pengobatan Cacar Air

Bismillahirrahmanirrahim

Rapa mila rabun

Raa psikin peke

Bareka laailahailallah

Bareka muhammadan rasulullah

Artinya:

Dengan menyebut nama Allah yang Maha

Pengasih lagi Maha Penyayang

Bersih darah dan tulang

Dari berkah Allah Tiada Ilah Selain Allah

Dari berkah Muhammad Rasulullah

Mantra pengobatan kawaro/cacar air ini berisi lima larik, yaitu larik pembuka, larik isi/tujuan, dan larik penutup. Larik pembuka dibuka dengan bacaan basmalah yang menunjukkan pengaruh dari agama Islam dan memohon bantuan kepada Allah SWT. Larik kedua dan ketiga adalah larik isi/tujuan yang menunjukkan tujuan pawang/sando dalam membacakan mantra, yaitu untuk membersihkan darah dan tulang pasien karena penyakit cacar air/kawaro dianggap berasal dari darah. Bahasa yang digunakan dalam larik kedua dan ketiga merupakan bahasa Bima kuno yang sudah tidak banyak digunakan oleh khalayak umum. Mantra ini kemudian ditutup dengan larik bareka laailahaillallah dan bareka muhammadan rasulullah yang menunjukkan permohonan kepada Allah SWT yang memberikan dan mampu menyembuhkan penyakit cacar yang diderita pasien.

Sebelum mulai membacakan mantra tersebut di atas, pawang/sando akan menyalakan 
kemenyan yang diletakkan di atas bara api, lalu asap kemenyan tersebut dibalurkan di seluruh badan pasien terutama yang terkena cacar. Setelah pembacaan mantra ini, pawang/sando akan mengoleskan lo'i keta kepada pasien karena dianggap mampu membantu penyembuhan penyakit cacar.

Fungsi mantra ini sebagaimana tujuan pembacaan mantra adalah untuk memohon kesembuhan untuk pasien yang menderita cacar air. Untuk menegaskan makna dan fungsi mantra, pawang/sando melakukan pengulangan dalam pembacaan larik awal dan larik penutuk mantra yang menunjukkan harapan dan pujian kepada Allah SWT serta Nabi Muhammad Rasulullah. Hal ini menunjukkan bahwa tidak ada yang dapat memberikan kesembuhan kecuali atas izin Allah SWT. Mantra pengobatan cacar ini serupa dengan mantra pengobatan sakit perut yang mendapat pengaruh dari agama Islam.

3. Mantra Pengobatan Patah Tulang

Bacaan mantra pengobatan patah tulang adalah sebagai berikut.

\section{Bismilah}

Tutu tinti

Tuki sraa

Rapu kapu

Rapu kamai nafsumu ese wawo kabusumu

Paragere ncanggeku ngara omi

Hu ha

Artinya

Dengan menyebut nama Allah

Pukul banting

Tahan semua

Rapat ditutup

Rapat dan datangkan nafsumu di atas

ubun-ubun

Paragere ncangge itu nama kamu

Hu ha

Mantra ini dibacakan oleh sando/pawang ketika mengobati pasien yang menderita patah tulang. Mantra ini dapat dibacakan ketika mengoles ramuan obat yang akan dibalurkan ke bagian tulang yang patah dan dibacakan pada air yang akan diminum oleh pasien. setelah diolesi obat, bagian tangan atau kaki yang patah akan dibebat menggunakan papan kayu ukuran sedang agar bagian yang patah tidak bergeser dan dapat segera menyatu.
Seperti mantra pengobatan lainnya, mantra pengobatan patah tulang dimulai dengan bacaan bismillah yang menandakan sando/pawang memohon kesembuhan kepada Allah. Di baris ketiga ada kalimat tuki saraa (tahan/sangga semua) yang bermakna harapan dan doa agar tulang yang patah disangga semua. Dalam mantra di atas, kata rapu yang bermakna "rapat" diulang-ulang pengucapannya oleh sando yang menandakan doa agar tulang yang patah dapat segera menyatu dan rapat kembali.

Adapun fungsi mantra ini adalah seperti tujuannya dirapalkan, yaitu untuk memohon kesembuhan pada pasien yang menderita patah tulang.

4. Mantra Pengobatan Luka-luka

Mantra pengobatan luka-luka dibacakan oleh sando ketika pasien menderita luka-luka, seperti luka bakar atau luka setelah kecelakaan. Adapun mantra pengobatan luka adalah sebagai berikut.

Bismilah

Maka ma nggee dei tando

Waja ma nggee dei wana

Bimbi ma nggee ta kui

Kulbi ma nggee dei kontu

Abdi ba ruma Allah SWT

Artinya

Dengan menyebut nama Allah

Maka tinggal di depan

Waja tinggal di kanan

Bimbi tingga di kiri

Kulbi tinggal di belakang/punggung

Abadi karena Allah SWT

Mantra ini dibacakan oleh sando ketika mengoleskan obat ke bagian tubuh pasien yang luka. Mantra pengobatan luka ini menggunakan beberapa kata bahasa Bima kuno sehingga sulit dipahami maksudnya.

5. Mantra Pengobatan Ncara Oi

Ungkapan mantra ncara oi:

Bismillah

Ya nabi

Busi ra waa inamu

Pana ra waa amamu

Ncai nahu ncai ndai ruma Allah SWT(3x)

Losa ra aina ru wara ma dei

Artinya

Dengan menyebut nama Allah 
Ya nabi

Dingin dibawa oleh ibumu

Panas dibawa oleh ayahmu

Jalan saya adalah jalan Allah SWT(3x)

Keluarlah jangan ada lagi di dalam

Ncara oi merupakan penyakit yang dianggap karena salah air ketika mandi. Pasien yang menderita penyakit ini mengalami demam dan meriang seperti yang dialami oleh penderita masuk angin. Mantra ini dilafalkan oleh sando ketika memberikan pengobatan kepada pasien dengan mengusap kedua telinga pasien, pusar, dan ujung kaki, lalu meniup (ufi) ubun-ubun pasien dengan tujuan hawa dingin keluar dari tubuh pasien. Setelah itu, sando memberikan air yang telah dibacakan mantra ini kepada pasien untuk diminum.

Lafadz mantra pengobatan ncara oi ini juga mendapat pengaruh agama Islam karena diawali dengan membaca basmalah dan diikuti dengan seruan Ya Nabi. Lalu di baris kelima, sando mengucapkan kalimat ncai nahu ncai ndai ruma Allah SWT sebanyak tiga kali untuk memberikan penegasan dan ditutup dengan kalimat Losa ra aina ru wara ma dei (keluarlah jangan ada di dalam) adalah perintah agar penyakit berupa panas yang ada di dalam tubuh agar segera keluar dari tubuh pasien.

Sebagaimana tujuannya dilafalkan, mantra ini berfungsi untuk mengusir penyakit panas dan demam yang ada di dalam tubuh pasien.

6. Mantra Pengobatan Gangguan Jin dan Setan Ungkapan mantra pengobatan gangguan jin:

\section{Bismillah}

Kulhuwallah

Ina rangga ngguwi

Ina rangga sasa

Asar nggomi dou ra sewe na wii

Ncai nahu ndama ruma

Peso kadoo mena wekim

Artinya

Dengan menyebut nama Allah

Katakanlah bahwa Dialah Allah

Ibu Rangga Ngguwi

Ibu Rangga sasa

Kamu orang yang di junjung tinggi

Jalan saya dengan Tuhan
Pergilah kalian yang jauh

Masyarakat Bima umumnya masih percaya dengan hal-hal mistis seperti gangguan jin dan setan. Penyakit karena gangguin jin dan setan seringkali tidak dapat dideteksi oleh ilmu modern. Sebelum mulai membaca mantra, sando meminta pasien untuk mandi dan menyiapkan kelapa kuning. Sando kemudian membacakan mantra kepada pasien.

Dalam mantra di atas, mantra dimulai dengan bacaan basmalah dan diikuti oleh bacaan qulhuwallah yang merupakan pengaruh agama Islam dan menandakan sando memohon bantuan Allah SWT untuk memberikan kesembuhan kepada pasien. Di baris terakhir ada kalimat Peso kadoo mena wekim (pergilah kalian yang jauh) yang bermakna sando/pawang mengusir jin yang ada dalam tubuh pasien.

\section{KESIMPULAN}

Mantra pengobatan yang ditemukan di desa Kaleo kecamatan Lambu adalah mantra pengobatan sakit perut, mantra pengobatan sakit cacar, mantra pengobatan patah tulang, mantra pengobatan luka-luka, mantra pengobatan ncara oi (demam), dan mantra pengobatan gangguan jin dan setan. Mantra-mantra pengobatan di desa Kaleo mendapat pengaruh agama Islam karena selalu diawali dengan bacaan basmalah. Lafadz mantra pengobatan juga banyak menggunakan bahasa Bima kuno yang tidak umum digunakan.

Mantra-mantra pengobatan desa Kaleo berfungsi sesuai dengan tujuan mantra-mantra tersebut dibacakan, yaitu untuk meminta kesembuhan dari sakit perut, cacar air, patah tulang, luka-luka, ncara oi (demam), dan gangguan jin. Adapun fungsi dari mantramantra ini sebagai folklor lisan adalah sebagai tata kelakuan kolektif yang merupakan bukti tata kelakuan kolektif masyarakat desa Kaleo.

SARAN

Berdasarkan hasil temuan dalam penelitian ini, saran peneliti terhadap pembaca atau peneliti-peneliti di bidang Sastra untuk menggali dan melakukan penelitian terkait dengan mantra ini. Sehingga eksistensi mantra sebagai salah satu bagian ilmu sastra dan kearifan lokal bisa tetap terjaga. Penelitian ini memiliki kendala dan hambatan yang di alami 
oleh peneliti. Peneliti memiliki kesulitan ketika ingin bertemu dengan pawang atau sando untuk mengambil data dikarenakan kesibukan pawang atau sando sebagai petani sehingga kesulitan mengatur waktu. Selain itu, pawang atau sando juga tidak mudah memberikan mantra yang mereka miliki karena itu merupakan rahasia turun temuran dan tidak bisa diberikan kesembarang orang.

\section{UCAPAN TERIMA KASIH}

Peneliti memberikan apresiasi yang tinggi serta ucapan terima kasih yang sebesarbesarnya kepada semua pihak yang telah terlibat dalam penelitian sehingga artikel ini bisa terselesaikan dengan baik.

\section{DAFTAR PUSTAKA}

Amir, A. (2013). Sastra Lisan Indonesia. Yogyakarta: Penerbit Andi.

Alaini, Nining Nur, Siti Djuwairiah, dan Siti Nur Djahratil. (2016). Mantra Pengobatan Cacar Etnis Bajo dan Etnis Mbojo di Kecamatan Sape, Kabupaten Bima: Sebuah Tinjauan Kontak Sastra. Mataram: Kantor Bahasa NTB.

Asmarini, Ni Putu, dll. (1998). Sastra Lisan Donggo. Jakarta: Pusat Pembinaan dan Pengembangan Bahasa.

Bascom, William R. (1965). "Four Functions of Folklore" dalam Alan Dundes The Study of Folklore. Englewood Cliff: Prentice Hall Inc.

Danandjaja, J. (2002). Folklor Indonesia: Ilmu Gosip, Dongeng, dan lain-lain. Jakarta: PT Grafiti Pres.

Duija, I Nengah. (2005). "Tradisi Lisan, Naskah, dan Sejarah: Sebuah Catatan Politik Kebudayaan". Wacana: Jurnal Pengetahuan dan Budaya. Vol. 7 No. 2. Diakses dari http://wacana.ui.ac.id/index.php/wjhi/ar ticle/view/296.

Endraswara, Suwardi. (2013). Folklor Nusantara: Hakikat, Bentuk, dan Fungsi. Yogyakarta: Penerbit Ombak.

\footnotetext{
-------------, ---------. (2009). Metodologi Penelitian Folklor: Konsep, Teori, dan Aplikasi. Yogyakarta: Medpress.
}

Pudentia, MPSS. (2008). Metodologi Kajian Sastra Lisan. Jakarta: Asosiasi Tradisi Lisan.

Sirat, Miftahul. (2015). Makna dan Fungsi Mantra pada Masyarakat Bima Tradisional dan Hubungannya dengan Pembelajaran Sastra di SMP. Diakses pada 25 Oktober 2020 dari http://eprints.unram.ac.id/9801/.

Sudikan, Setya Yuwana. 2001. Metode Penelitian Sastra Lisan. Surabaya: Citra Wacana.

Sorayah, Yayah. (2014). Fungsi dan Makna Mantra Tandur di Desa Karangnunggal Kecamatan Cibeber Kabupaten Cianjur. Jurnal Bahtera Sastra: Antologi Bahasa dan Sastra Indonesia. Vol. 2 No. 2. Diakses pada 25 Oktober 2020 https://ejournal.upi.edu/index.php/BS Antologi_Ind/article/view/646. 